\title{
Expression Analysis of Rice Defense-Related Genes in Turfgrass in Response to Magnaporthe grisea
}

\author{
Young-Ki Jo, Guo-Liang Wang, and Michael J. Boehm
}

Department of Plant Pathology, The Ohio State University, Columbus 43210.

Accepted for publication 25 August 2006.

\begin{abstract}
Jo, Y.-K., Wang, G.-L., and Boehm, M. J. 2007. Expression analysis of rice defense-related genes in turfgrass in response to Magnaporthe grisea. Phytopathology 97:170-178.

Magnaporthe grisea (anamorph = Pyricularia grisea) causes blast on rice (Oryza sativa) and gray leaf spot on turfgrass. Gray leaf spot is a serious disease on St. Augustinegrass (Stenotaphrum secundatum), perennial ryegrass (Lolium perenne), and tall fescue (Festuca arundinacea). Virulence assays performed in this study revealed that $M$. grisea collected from rice could also cause disease on St. Augustinegrass and tall fescue. One rice isolate, Che86061, caused similar disease reactions on susceptible cultivars of rice and St. Augustinegrass and an incompatible inter-

defense-related genes are expressed in rice and St. Augustinegrass, a rice cDNA library was screened using pooled cDNAs derived from $M$. griseainfected St. Augustinegrass. Thirty rice EST (expressed sequence tag) clones showing differential expression in St. Augustinegrass following $M$. grisea inoculation were identified and classified into six putative functional groups. Northern blot analyses of seven EST clones that collectively represented each putative functional group confirmed that the expression of five out of seven EST clones was similar in both rice and St. Augustinegrass. This study represents one of the first attempts to use a broad-scale genomic approach and resources of a model monocot system to study defense gene expression in St. Augustinegrass following $M$. grisea infection.
\end{abstract} action on resistant cultivars of both species. To explore whether similar
Magnaporthe grisea (T.T. Herbert) Yaegashi \& Udagawa (anamorph $=$ Pyricularia grisea (Cooke) Sacc.) causes disease on more than 50 graminaceous species including important food crops and cultivated turfgrasses $(24,28,30)$. M. grisea causes blast on rice (Oryza sativa L.) and gray leaf spot (GLS) on turfgrass $(30,33)$. GLS is a serious disease of St. Augustinegrass (Stenotaphrum secundatum (Walt.) Kuntze), perennial ryegrass (Lolium perenne L.), and tall fescue (Festuca arundinacea Schreb.) throughout the United States $(13,22,26,29,35)$. The disease is especially devastating on newly planted turfgrass (30).

Symptoms of GLS on St. Augustinegrass are distinctive brown spots with gray centers. Tiny lesions develop rapidly into distinct spots that later expand across the entire leaf blade. On perennial ryegrass, initial symptoms appear as tiny pinprick lesions and often go unnoticed or are mistaken as other leaf spot diseases such as those caused by Drechslera or Bipolaris species. Small spots quickly turn into water-soaked lesions, coalesce and progress rapidly to necrosis of entire leaves during hot $\left(26\right.$ to $\left.29^{\circ} \mathrm{C}\right)$ humid weather (30). During periods of favorable environmental conditions, GLS may severely damage susceptible species. An adequate fertility program and cultural practices designed to minimize the duration of prolonged leaf wetness and alleviate stress are recommended to reduce the risk of GLS. However, preventive fungicide applications are typically required to manage GLS on intensively cultivated turfgrass.

As the staple food for about half of the world's population, rice is fast becoming the model plant for monocot species in molecular biology and genomics studies. In rice, numerous molecular markers have been developed for mapping and cloning resis-

Corresponding author: M. J. Boehm; E-mail address: boehm.1 @ osu.edu

*The $e$-Xtra logo stands for "electronic extra" and indicates that Figure 1 appears in color online.

DOI: 10.1094/PHYTO-97-2-0170

(c) 2007 The American Phytopathological Society tance genes against $M$. grisea that can be subsequently used for selecting and improving blast resistance in rice breeding programs. About 30 major resistance genes conferring complete resistance to $M$. grisea and about 10 minor genes, also called quantitative trait loci (QTLs), that confer partial resistance, have been identified $(18,21,36,37)$. Large-scale collections and improvements of disease-resistant germplasm have also been made in turfgrass breeding programs. For example, St. Augustinegrass germplasm introduced from Africa provided the foundation for developing cultivars with enhanced disease and insect pest resistance $(1,5)$. Partial resistance to GLS within perennial ryegrass also was recently identified in European and North American germplasm (3).

Compared with the advanced developments in rice, molecular genetic approaches for developing markers, mapping resistance genes, and studying the molecular mechanisms of turfgrassmicrobe interactions are only in their early stages. However, the presence of conserved synteny in $M$. grisea resistance QTL between rice and different graminaceous species suggests that similar resistance mechanisms may be employed in rice and turfgrass $(3,6)$. This raises the possibility of exploiting genomic resources from rice, such as the large collection of expression sequence tags (ESTs) that currently exists, to gain knowledge about the turfgrass $-M$. grisea interaction. The objective of this study was to determine whether defense-related genes present in rice are also expressed in turfgrass following infection with M. grisea.

\section{MATERIALS AND METHODS}

Plant materials. Five rice cultivars (IR31917, CO39, 75-1-127, C101A51, and Nipponbare) differing in their susceptibility to $M$. grisea were used in this study $(15,18)$. C101A51 and 75-1-127 are near-isogenic lines derived from introgressions of the resistance gene Pi2 in CO39 and Pi9 in IR31917, respectively. Nipponbare is one of the rice cultivars that has been widely used 
for molecular genetic studies and its genome is completely sequenced (10). St. Augustinegrass cvs. Floratam, FX-10, FX-33, PI290888, and PI300130, and tall fescue cvs. Tar Heel and Coronado were also selected based on differences in their susceptibility to GLS according to previous field evaluations $(1,4,5,8,14)$.

Plants were grown in the greenhouse $\left(25\right.$ to $\left.28^{\circ} \mathrm{C}\right)$. Rice and tall fescue seeds were sown (30 seeds per 15 -cm-diameter pot) in potting mix (Metro-Mix, Sun Gro Horticulture Distribution Inc., Bellevue, WA). Rice was grown for 3 weeks until the four- to five-leaf stage and tall fescue was grown for 8 weeks before inoculation. Initial stolon segments of St. Augustinegrass cultivars were grown in trays $(53 \times 27 \times 6 \mathrm{~cm})$ and vegetatively propagated. Terminal stolons $(30 \mathrm{~cm})$ containing three to five shoots were cut and transferred to new trays filled with fresh potting mix. Plants were grown for 8 weeks prior to use. Plants were fertilized every 15 days with a water-soluble Peters 20-20-20 (NP-K) fertilizer.

M. grisea isolates. Six M. grisea isolates (ML33, KJ201, PO66, Che86061, C9240-1, and CHNOS60-2-3), originally recovered from rice $(15,18)$, and one isolate (SSOH) from St. Augustinegrass were used in this study. These $M$. grisea isolates originated from different geographic regions: ML33 from Mali; KJ201 from South Korea; PO6-6 from the Philippines; Che86061, C9240-1, and CHNOS60-2-3 from China; and SSOH from Florida. Millet grain inoculum of each isolate was prepared and stored at $-20^{\circ} \mathrm{C}$ as described previously (17).

Two weeks before inoculation, millet inoculum of each isolate was cultured on oatmeal agar medium (32). A single millet seed was placed in the center of each oatmeal agar plate $(8-\mathrm{cm}-$ diameter) and incubated in the dark at $25^{\circ} \mathrm{C}$ for 7 days. Plates were then transferred to a light chamber $\left(24 \mathrm{~h}\right.$ light at $\left.28^{\circ} \mathrm{C}\right)$ and incubated for an additional 7 days to induce sporulation.

Virulence assays. The virulence of each $M$. grisea isolate was evaluated on both rice and turfgrass. Specifically, rice cvs. IR31917, CO39, 75-1-127, C101A51, and Nipponbare; St. Augustinegrass cvs. Floratam, FX-10, FX-33, PI290888, and PI300130; and tall fescue cvs. Tar Heel and Coronado were used. Conidia collected from 14-day-old $M$. grisea colonies were used for inoculation. The concentration of conidia in each suspension was estimated with a hemacytometer (Hausser Scientific, Horsham, PA). Conidial suspensions were diluted to a final concentration of $2 \times 10^{5}$ conidia $\mathrm{ml}^{-1}$. Tween 20 (Fisher Scientific, Fair Lawn, NJ) was added to all spore suspensions to achieve a final concentration of $0.02 \%$ ( $\mathrm{vol} / \mathrm{vol})$ prior to inoculation.

Plants were inoculated as described previously (18). Mock inoculations with a $0.02 \%$ solution of Tween 20 were included in each assay. Inoculated plants were kept in the dark $\left(25^{\circ} \mathrm{C} ; 100 \%\right.$ relative humidity) for $24 \mathrm{~h}$ and then transferred to a controlled environment chamber ( $12 \mathrm{~h}$ photoperiod, $500 \mu \mathrm{E}, 400$ to $700 \mathrm{~nm}$ wavelength, 20 to $26^{\circ} \mathrm{C}$, and 60 to $80 \%$ relative humidity). Ten leaves from each plant were randomly collected at 7 days after inoculation and disease severity was assessed using the following scale (20): 0 = asymptomatic; 1 = pinhead-sized brown specks; $2=1.5 \mathrm{~mm}$ brown spots; $3=2$ to $3 \mathrm{~mm}$ gray spots with brown margins; $4=$ many elliptical gray spots longer than $3 \mathrm{~mm}$; and $5=$ coalesced lesions infecting $50 \%$ or more of the leaf area. The virulence assay of each $M$. grisea isolate was performed twice for each plant cultivar. The data from two replicates of each assay were pooled and analyzed using the nonparametric KruskalWallis chi-square test (9) (PROC NPAR1WAY; SAS 9.1; SAS Institute, Cary, NC).

Rice cDNA library screening with reverse northern blot analysis. Reverse northern blot analyses $(19,38)$ were conducted to determine whether rice defense-related homologous genes were present in St. Augustinegrass. An M. grisea-inoculated rice cDNA library previously constructed by Jantasuriyarat et al. (15) was screened with cDNA prepared from $M$. grisea-inoculated St. Augustinegrass. EST sequence information is provided online by the National Science Foundation (Magnaporthe grisea Oryza sativa $[\mathrm{MGOS}]$ interactive database).

A total of 9,216 EST clones were screened from the OSJNEd library representing a profile of gene expression in the incompatible (resistant) reaction of rice cv. Nipponbare at $24 \mathrm{~h}$ after M. grisea isolate C9240-1 inoculation. For each membrane, two 384-well microtiter plates containing 768 EST clones were spotted twice onto a nylon membrane $(12 \times 8 \mathrm{~cm})\left(\right.$ Hybond $\mathrm{N}^{+}$, Amersham Biosciences, Piscataway, NJ) with a high density replicating tool (V\&P Scientific Inc., San Diego, CA). Duplicated spots of the same clone on the membrane served as a quality check of hybridization. Twelve membranes were prepared. Spotted membranes were incubated on Luria-Bertani (LB) agar media amended with carbenicillin (Research Products International Corp., Mt. Prospect, IL) at $100 \mu \mathrm{g} \mathrm{ml} \mathrm{I}^{-1}$ at $36^{\circ} \mathrm{C}$ for 20 to $24 \mathrm{~h}$ until colonies grew to $2 \mathrm{~mm}$ in diameter. The membranes were processed as described previously $(12,25)$.

To determine genes associated with early plant defense responses (within $24 \mathrm{~h}$ after infection), the following three cDNA probes were prepared and used to screen the rice ESTs: (i) Floratam at $24 \mathrm{~h}$ after inoculation with $M$. grisea isolate Che86061; (ii) FX-10 at $24 \mathrm{~h}$ after inoculation with $M$. grisea isolate Che86061; and (iii) FX-10 at $24 \mathrm{~h}$ after mock inoculation with $0.02 \%$ Tween 20. Total RNA was isolated from St. Augustinegrass by the phenol-guanidine isothiocyanate method (TRIZOL, Invitrogen, Carlsbad, CA). cDNA was synthesized using the Reverse Transcription System (Promega, Madison, WI) and $0.5 \mu \mathrm{g}$ of the cDNA was labeled with ${ }^{32} \mathrm{P}-\mathrm{dCTP}$. The membranes were hybridized with one radiolabeled cDNA probe in modified Church buffer (25) (denatured 1\% [wt/vol] salmon sperm DNA, $1 \mathrm{mM}$ EDTA, $0.5 \mathrm{M}$ phosphate buffer [pH 7.2], and 7\% [wt/vol] sodium dodecyl sulfate [SDS]) with continuous shaking at $60^{\circ} \mathrm{C}$ for $24 \mathrm{~h}$. Membranes were washed with $2 \times \mathrm{SSC}(1 \times \mathrm{SSC}$ is $0.15 \mathrm{M} \mathrm{NaCl}$ plus $0.015 \mathrm{M}$ sodium citrate) $/ 0.1 \% \mathrm{SDS}, 1 \times \mathrm{SSC} / 0.1 \% \mathrm{SDS}$, and $0.5 \times \mathrm{SSC} / 0.1 \% \mathrm{SDS}$, respectively, for $10 \mathrm{~min}$ (25). Washed membranes were covered in plastic wrap and exposed to $\mathrm{X}$-ray film (Eastman Kodak Company, Rochester, NY) at $-80^{\circ} \mathrm{C}$. Images were developed in an X-ray film processor (Konica Medical Imaging Inc., Wayne, NJ). The hybridization experiment was done twice with cDNA probes made from two biological replicates.

EST clones showing differential hybridization intensities with St. Augustinegrass cDNA probes were selected for a second round of screening. EST clones were cultured in 96-well microtiter plates containing LB broth with carbenicillin at $100 \mu \mathrm{g} \mathrm{ml}^{-1}$. Each microtiter plate included one well that contained Escherichia coli with the pBluescript vector as a negative control and one well that contained the rice ubiquitin cDNA clone (OSJNEa03L15 in the MGOS database) as an internal positive control. For each membrane, EST clones in a 96-well microtiter plate were spotted twice on the same nylon membrane $(12 \times 8 \mathrm{~cm})$ and hybridized with each of the three St. Augustinegrass cDNA probes as aforementioned. The probes were made from two biological, independent replicates. Autoradiographs were scanned (Epson Perfection 4870, Long Beach, CA) and the intensity of hybridization was quantified using image analysis software, ImageJ (provided online by the National Institutes of Health [NIH]). Hybridization signals were corrected for the level of the negative control hybridization for clones containing the empty pBluescript vector and normalized as (intensity of the EST clone)/(intensity of the ubiquitin clone).

EST clones showing differential hybridization intensities with St. Augustinegrass cDNA probes were selected. The predicted amino acid sequence of each selected EST was used to classify each clone into a functional group according to the National Center for Biotechnology Information (NCBI) database of Clusters of Orthologous Groups (COGs) (provided online by NCBI).

Northern blot analyses. Seven rice EST clones assigned to six different putative functional groups of COGs were selected and 
their expression over time was determined using northern blot analysis (25). Total RNA was extracted from St. Augustinegrass cv. FX-10 and rice cv. C101A51 at 0, 6, 12, 24, 48, and $72 \mathrm{~h}$ after inoculation with $M$. grisea isolate Che86061 or after mock inoculation with $0.02 \%$ Tween 20 . Ten micrograms of total RNA was separated on a $1.4 \%$ agarose gel and then transferred to nylon membranes in $5 \times \mathrm{SSC} / 10 \mathrm{mM} \mathrm{NaOH}$ buffer for $12 \mathrm{~h}$ (25). Probes were prepared by restriction enzyme digestions (EcoRI and XhoI, New England Biolabs, Beverly, MA) of EST plasmid clones or by polymerase chain reaction (PCR) amplification using M13 forward and reverse primers. For each reaction, $40 \mathrm{ng}$ of DNA was labeled with ${ }^{32} \mathrm{P}$-dCTP using a random primer labeling kit (Amersham Pharmacia Biotech, Piscataway, NJ) and unincorporated nucleotides were removed with a ProbeQuant Micro Column (Amersham Biosciences). The hybridization procedure was the same as in the reverse northern blot analyses except that the incubation temperature was $55^{\circ} \mathrm{C}$ and the blots were washed with $2 \times \mathrm{SSC} / 0.1 \% \mathrm{SDS}$ for $10 \mathrm{~min}$.

Hybridization with each EST probe was performed twice using two different RNA blots prepared from independent plant inoculation experiments. Membranes were used no more than two times after stripping bound isotope within a $0.1 \%$ SDS solution at $100^{\circ} \mathrm{C}$ for $5 \mathrm{~min}$. After the last hybridization, the membrane was stripped and hybridized with the 18S ribosomal DNA probe (OSJNEd01B09 in the MGOS database). The resulting band was used as an internal loading control. Autoradiographs were scanned and quantified using the ImageJ digital image analysis software as describe previously. The signal intensity of each band was subtracted from the level of background hybridization and normalized as (intensity of a band)/(intensity of an 18S rRNA band in the same lane). The relative hybridization intensity (as compared with the intensity at the 0-h time point) of each EST clone at $6,12,24,48$, and $72 \mathrm{~h}$ after inoculation was determined.

\section{RESULTS}

Virulence assays. The virulence of the seven $M$. grisea isolates was significantly different among host plants $(P<0.0001$; Table 1). Among them, two rice isolates (CHNOS60-2-3 and KJ201) caused disease on both tall fescue and St. Augustinegrass. Isolates CHNOS60-2-3 and KJ201 produced water-soaked lesions or gray spots with brown borders on tall fescue cv. Tar Heel (median disease severity $=3$ ) but not cv. Coronado (median disease severity $=0$ to 1 ). Isolates $\mathrm{KJ} 201$ and Che86061 caused severe blight on St. Augustinegrass cv. Floratam (median disease severity $=4$ to 5) and rice cv. Nipponbare (median disease severity $=5$ ) but did not cause disease on St. Augustinegrass cv. FX-10 or rice cvs. C101A51, 75-1-127, and IR31917 (Table 1). Isolate Che86061 was chosen for subsequent reverse northern and northern blot analyses because of its similar virulence reactions on both rice and St. Augustinegrass (Fig. 1). Isolate SSOH appeared to be more virulent on St. Augustinegrass cv. Floratam (median disease severity = 5) (Fig. 1) and PI290888 (median disease severity = 3) than on the other cultivars tested.

Expression of rice defense-related genes in St. Augustinegrass following $M$. grisea inoculation. Large-scale EST screening using reverse northern hybridization was used to identify rice genes that were differentially expressed in St. Augustinegrass. An example highlighting the differences between the hybridization intensities with mock control, incompatible, and compatible St. Augustinegrass cDNA probes is shown in Figure 2. Thirty rice EST clones showing different hybridization signals following $M$. grisea inoculation were selected and their putative functions according to the NCBI COG database are listed in Table 2. The selected ESTs were classified into the following six putative functional groups: (i) cellular processes and signaling (10 ESTs); (ii) information storage and processing (four ESTs); (iii) metabolism (seven ESTs); and (iv) unclear function (nine ESTs). The 10 ESTs assigned to the cellular processes and

TABLE 1. Virulence of Magnaporthe grisea isolates used in this study

\begin{tabular}{|c|c|c|c|c|c|c|c|c|c|c|c|c|c|c|}
\hline \multirow[b]{3}{*}{ Plant } & \multicolumn{12}{|c|}{ M. grisea from Oryza sativa } & \multirow{2}{*}{\multicolumn{2}{|c|}{$\begin{array}{c}\begin{array}{c}\text { M. grisea from } \\
\text { Stenotaphrum } \\
\text { secundatum }\end{array} \\
\mathrm{SSOH}\end{array}$}} \\
\hline & \multicolumn{2}{|c|}{ PO6-6 } & \multicolumn{2}{|c|}{ ML33 } & \multicolumn{2}{|c|}{ CHNOS60-2-3 } & \multicolumn{2}{|c|}{ KJ201 } & \multicolumn{2}{|c|}{ C9240-1 } & \multicolumn{2}{|c|}{ Che86061 } & & \\
\hline & Median $^{\mathrm{a}}$ & $\begin{array}{c}\text { Mean } \\
\text { rank }\end{array}$ & Median & $\begin{array}{c}\text { Mean } \\
\text { rank }\end{array}$ & Median & $\begin{array}{c}\text { Mean } \\
\text { rank }\end{array}$ & Median & $\begin{array}{c}\text { Mean } \\
\text { rank }\end{array}$ & Median & $\begin{array}{c}\text { Mean } \\
\text { rank }\end{array}$ & Median & $\begin{array}{l}\text { Mean } \\
\text { rank }\end{array}$ & Median & $\begin{array}{l}\text { Mean } \\
\text { rank }\end{array}$ \\
\hline \multicolumn{15}{|l|}{ Oryza sativa } \\
\hline $\mathrm{CO} 39$ & 5 & 222.3 & 5 & 212.0 & 5 & 193.5 & 5 & 189.5 & 5 & 220.8 & 2 & 144.9 & 0 & 189.5 \\
\hline IR31917 & 5 & 207.7 & 5 & 212.0 & 4 & 153.2 & 1 & 112.3 & 5 & 220.3 & 1 & 131.8 & 0 & 112.3 \\
\hline Nipponbare & 3 & 180.5 & 5 & 203.0 & 5 & 208.6 & 5 & 210.4 & 0 & 110.5 & 5 & 219.1 & 0 & 210.4 \\
\hline C101A51 & 0 & 74.6 & 1 & 96.6 & 4 & 153.7 & 0 & 43.6 & 0 & 105.5 & 1 & 102.3 & 0 & 43.6 \\
\hline $75-1-127$ & 0 & 59.0 & 0 & 81.7 & 0 & 51.0 & 0 & 37.5 & 0 & 155.5 & 0 & 49.0 & 0 & 37.5 \\
\hline \multicolumn{15}{|l|}{ S. secundatum } \\
\hline Floratam & 0 & 62.9 & 0 & 69.1 & 3 & 103.2 & 4 & 172.6 & 0 & 100.5 & 5 & 208.9 & 5 & 172.6 \\
\hline FX10 & 0 & 82.4 & 0 & 38.5 & 0 & 46.0 & 1 & 68.6 & 0 & 95.5 & 0 & 52.2 & 0 & 68.6 \\
\hline FX33 & 0 & 66.8 & 1 & 101.1 & 0 & 54.5 & 2 & 103.6 & 0 & 100.5 & 0 & 89.6 & 0 & 103.6 \\
\hline PI290888 & 1 & 129.5 & 2 & 116.8 & 4 & 175.9 & 4 & 181.2 & 0 & 95.5 & 2 & 115.9 & 3 & 181.2 \\
\hline PI300130 & 0 & 83.8 & 2 & 116.1 & 1 & 96.7 & 2 & 109.1 & 0 & 95.5 & 2 & 133.9 & 0 & 109.1 \\
\hline \multicolumn{15}{|l|}{$\begin{array}{l}\text { Festuca } \\
\quad \text { arundinacea }\end{array}$} \\
\hline Tar Heel & 1 & 144.7 & 1 & 92.7 & 3 & 135.6 & 3 & 146.1 & 0 & 100.5 & 0 & 99.9 & 0 & 146.1 \\
\hline Coronado & 1 & 131.9 & 1 & 104.5 & 1 & 74.2 & 0 & 71.6 & 0 & 95.5 & 0 & 98.7 & 0 & 71.6 \\
\hline $\begin{array}{l}\text { Kruskal-Wallis } \\
\text { chi-square }\end{array}$ & & 176.5 & & 159.4 & & 162.4 & & 166.8 & & 174.8 & & 136.7 & & 189.5 \\
\hline$P$ value & & $<0.0001$ & & $<0.0001$ & & $<0.0001$ & & $<0.0001$ & & $<0.0001$ & & $<0.0001$ & & $<0.0001$ \\
\hline $\mathrm{LSD}_{0.05}(\text { Ranks) })^{\mathrm{b}}$ & & 43.9 & & 43.9 & & 43.9 & & 43.9 & & 43.9 & & 43.9 & & 43.9 \\
\hline
\end{tabular}

${ }^{a}$ Median disease severity of 10 leaves at 7 days after $M$. grisea inoculation with the following rating scales: $0=$ asymptomatic; $1=$ pinhead-sized brown specks; $2=1.5 \mathrm{~mm}$ brown spots; $3=2$ to $3 \mathrm{~mm}$ gray spots with brown margins; $4=$ many elliptical gray spots longer than $3 \mathrm{~mm}$; and $5=$ coalesced lesions infecting $50 \%$ or more of the leaf area.

${ }^{\mathrm{b}}$ Nonparametric least significant difference (LSD) is calculated as $z \times \operatorname{sqrt}[k \times(N+1) / 6]$ in which $z$ is the standard normal statistic $(\approx 2$ for $P=0.05)$, sqrt is the square root, $k$ is the number of treatments, and $N$ is total data points. $\operatorname{LSD}_{0.05}=2 \times \operatorname{sqrt}[12 \times(240+1) / 6]=43.9$. 
signaling category were further divided into the following subcategories: defense mechanisms (two ESTs); signal transduction mechanisms (five ESTs); and posttranscriptional modification, protein turnover, and chaperones (three ESTs).

The hybridization signal of 17 EST clones was increased and that of three clones was decreased by more than $50 \%$, respectively, in the incompatible (resistant) reaction of $M$. grisea-inoculated cv. FX-10 relative to the mock-inoculated cv. FX-10 (Table 2 ). In the compatible (susceptible) reaction of $M$. grisea-inoculated cv. Floratam, the hybridization signal of 12 clones was increased and that of two clones was decreased by more than $50 \%$, respectively, compared with the mock-inoculated cv. FX-10 (Table 2). The hybridization signal of many ESTs was similar in both the compatible and the incompatible reactions. The signal intensity of 11 EST clones was increased and that of one clone was decreased by more than $50 \%$ in both compatible and incompatible reactions (Table 2).

Time-course expression of the selected EST clones in St. Augustinegrass and rice postinoculation. The following seven ESTs collectively representing the various functional groups were selected and their expression was evaluated at five time points after inoculation using northern blot analysis: two ESTs
(OSJNEd01P14 and OSJNEd12G02) from defense mechanisms; two (OSJNEd15N10 and OSJNEd6H06) from signal transduction mechanisms; two (OSJNEd13E08 and OSJNEd17B11) from information storage and processing; and one (OSJNEd02O23) from posttranscriptional modification, protein turnover, and chaperones. Results showed that transcript accumulation of five of the seven clones increased approximately two- to fivefold in both St. Augustinegrass cv. FX-10 and rice cv. C101A51 between 6 and $72 \mathrm{~h}$ after inoculation with M. grisea isolate Che86061 (Fig. $3)$. For example, the signal intensity from EST OSJNEd01P14 encoding a $\beta$-1,3-glucanase increased approximately twofold $12 \mathrm{~h}$ postinoculation (Fig. 3A) and the signal from OSJNEd12G02 encoding a peroxidase increased approximately threefold (Fig. 3D). The expression of two ESTs, OSJNEd15N10 and OSJNEd17B11, did not significantly change in either St. Augustinegrass or rice compared with the mock-inoculated control (data not shown).

\section{DISCUSSION}

Rice is the model plant of monocot species for molecular biology and genome studies. The rice EST analysis has provided

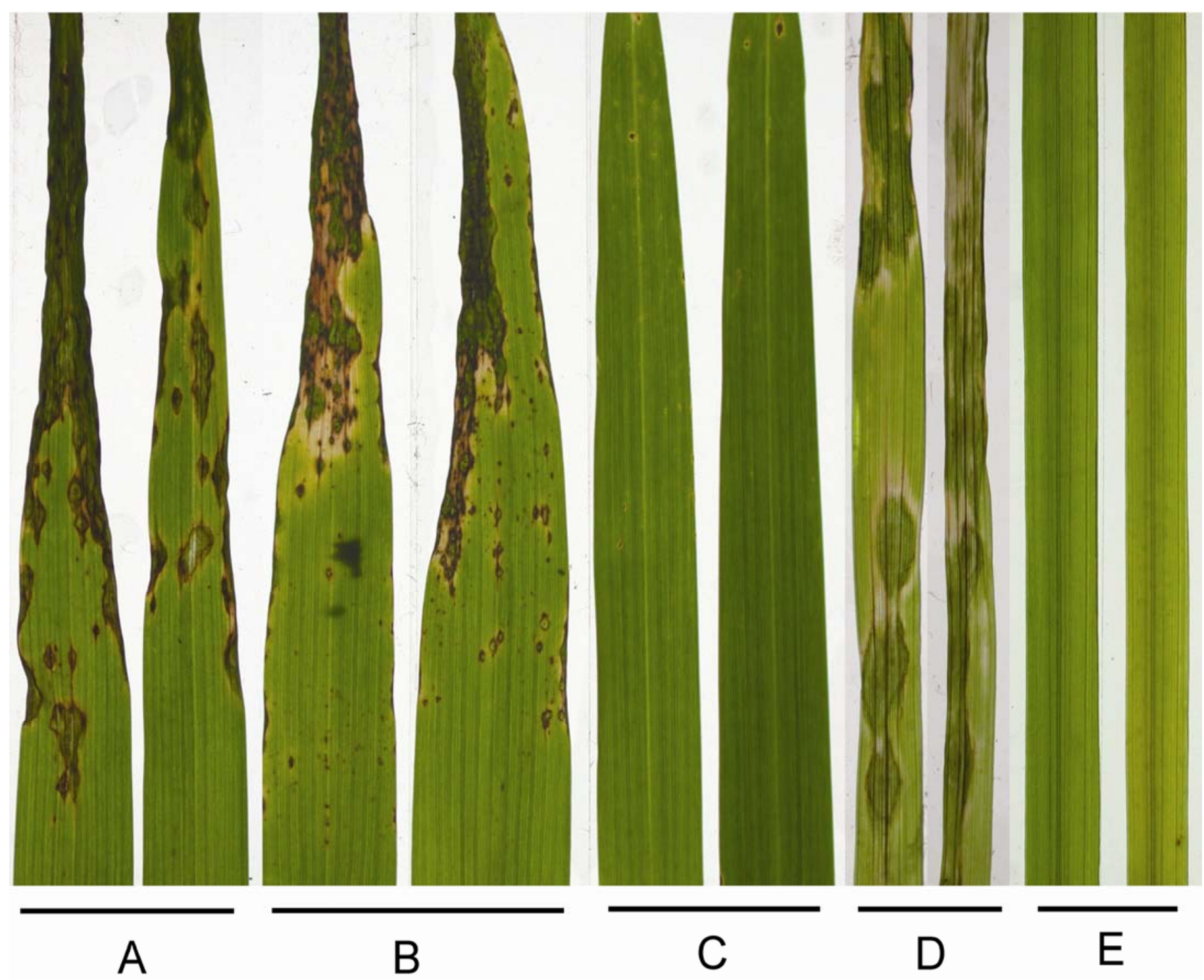

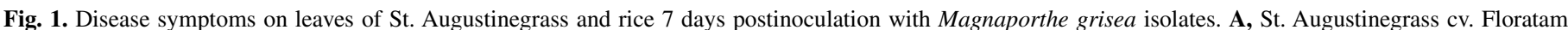

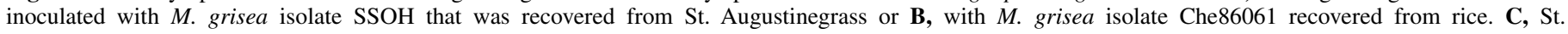
Augustinegrass cv. FX-10 inoculated with Che86061. D, Rice cv. Nipponbare and E, C101A51 inoculated with Che86061. 
a powerful tool to identify unique genes and to profile gene expression of the defense response following $M$. grisea infection (15). Compared with rice, relatively little is known about the molecular mechanisms mediating defense responses in turfgrass. Recently, a homologous avirulence gene was identified in both perennial ryegrass and rice isolates of $M$. grisea (23), but the molecular mechanism of turfgrass responding to infection by $M$. grisea is still largely unknown. In this study, we found a phenotypic similarity between rice blast and St. AugustinegrassGLS interactions and identified defense-related genes conserved in both St. Augustinegrass and rice.

Our virulence assay clearly showed that $M$. grisea isolates from rice can also cause GLS on several cultivars of St. Augustinegrass and tall fescue. Using this similar disease reaction by the same $M$. grisea isolate, and genetic resources of $M$. grisea-inoculated rice cDNA libraries and their sequence database, rice ESTs potentially associated with M. grisea infection in St. Augustinegrass were identified by two different northern hybridization analyses in this study.

The host range of $M$. grisea has been widely studied and cross infectivity of $M$. grisea has been well documented $(17,31,34)$. Virulence assays conducted in Japan (17) and Morocco (2) revealed that some $M$. grisea isolates can infect both rice and turfgrass. Two rice isolates (CHNOS60-2-3 and KJ201) tested in this study produced typical GLS symptoms on tall fescue cv. Tar Heel and St. Augustinegrass cvs. Floratam and PI290888. Particularly, one rice isolate, Che86061, showed clear compatibility (median disease severity $=5$ ) with both rice cv. Nipponbare and St. Augustinegrass cv. Floratam but incompatibility (median disease severity $=0$ to 1 ) with rice cvs. C101A51, IR31917, and 751-127 and St. Augustinegrass cvs. FX-10 and FX-33 (Table 1; Fig. 1). Cross infectivity of turfgrass isolates of $M$. grisea to rice as previously shown by Benkirane et al. (2) in Morocco and Kato et al. (17) in Japan could not be determined in this study. Farman (7) showed previously that cross infectivity of $M$. grisea to turfgrass and other cereal crops may not be significant in the United States and that the turfgrass isolates of M. grisea evaluated were distantly related to rice isolates based on DNA finger- printing. Further virulence assays using more turfgrass isolates recovered from the United States will be needed to confirm the cross infectivity of $M$. grisea on rice and turfgrass, which will also be important to understand the evolutionary relationship of $M$. grisea isolates infecting rice and turfgrass.

Using reverse northern blot analysis, 30 EST clones that showed increased or decreased accumulation of transcripts in $M$. grisea-inoculated St. Augustinegrass were identified from 9,216 rice EST clones in the OSJNEd cDNA library, representing a profile of gene expression in the defense response of St. Augustinegrass to $M$. grisea. Many ESTs screened in this study have been previously documented to be induced at the transcriptional level in rice and other plants responding to pathogens or other abiotic stresses, including pathogenesis-related proteins, signal transduction proteins associated with reversible protein phosphorylation, and proteins involved in biosynthetic pathways associated with plant defense. Subsequent northern blot analysis of several ESTs representing different functional groups further supported the similarity in the expression of the selected EST clones in rice and St. Augustinegrass after M. grisea infection. The expression of 18 EST clones increased more than $50 \%$ in the reverse northern hybridization in incompatible and/or compatible reactions of St. Augustinegrass with $M$. grisea. When seven EST clones were analyzed for transcription accumulation over time using northern blot hybridization, the expression of four of these seven ESTs was found to increase approximately two- to fivefold postinoculation in both St. Augustinegrass and rice.

There was some variability of the timing and level of induction postinoculation between biological replicates and inconsistencies between rice and St. Augustinegrass in the reverse northern and northern hybridization analyses. These differences are likely due to variations originating from the heterologous and interspecific hybridization approaches used in this study. EST clones were developed from rice cv. Nipponbare but were used for hybridizations with cDNA from St. Augustinegrass and rice cv. C101A51. The different genetic backgrounds of these plants may cause variations in EST expression levels, as determined by hybridization signal intensity. For example, a limitation of
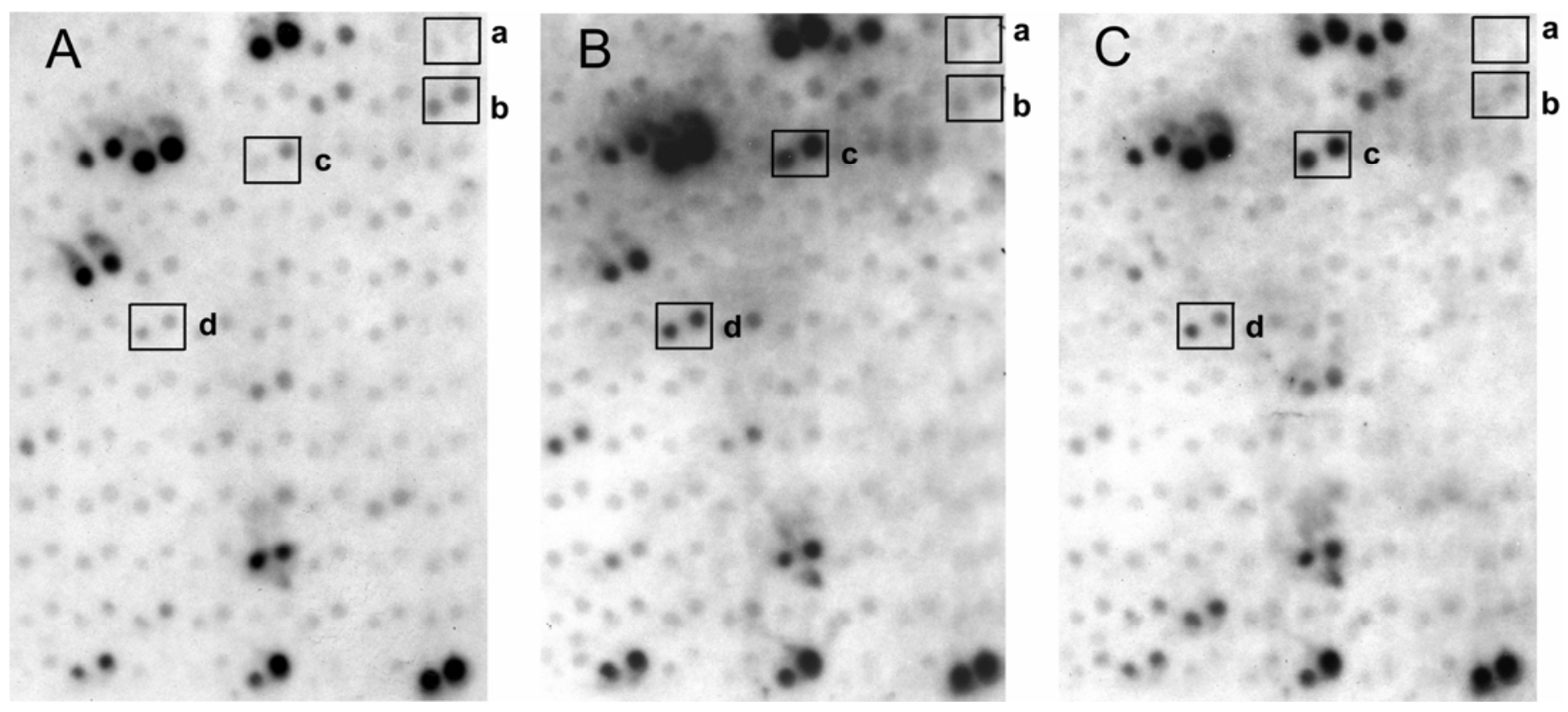

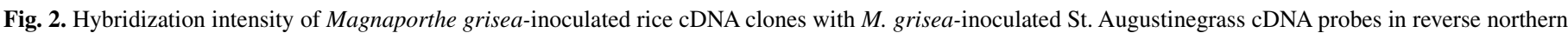

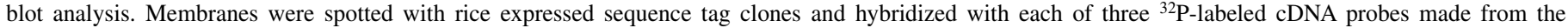

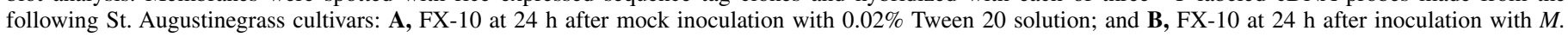

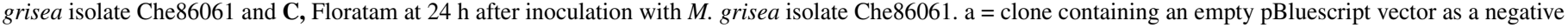

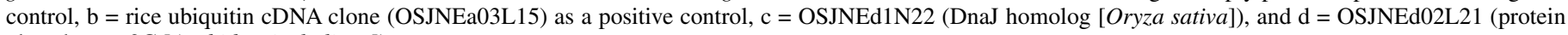
phosphatase 2C [Arabidopsis thaliana]). 
screening EST clones from the rice cDNA library using reverse northern blot analysis is that only ESTs having greater than $70 \%$ sequence identity with St. Augustinegrass transcripts will be detected with the melting temperature and washing stringency used in this study. Unique genes associated with plant defense mechanisms responding to M. grisea in St. Augustinegrass or rice would not be identified in this study. In the northern blot analysis, the different intensity of hybridization and different expression patterns between St. Augustinegrass and rice also may result from the use of the heterologous probes.

The online accessible rice EST sequence database (MGOS) allowed us to perform a virtual northern analysis of the EST clones screened in this study. The expression level of each of these ESTs in the virtual northern analysis was determined as the frequency of consensus sequences (contigs) found within different rice (cv. Nipponbare) cDNA libraries. The virtual northern analysis was conducted for the ESTs only if more than 30 contigs corresponding to the EST were found from the rice cDNA libraries. More than a fivefold change in the frequency was considered as significant. The expression levels of some EST clones determined via the virtual northern procedure showed a pattern similar to those determined with the reverse northern and northern hybridization analyses (Table 3). For example, the expression of two rice EST clones that encode a glucanase

TABLE 2. Expression levels of expressed sequence tags (ESTs) clones by the reverse northern blot analysis

\begin{tabular}{|c|c|c|c|c|c|c|}
\hline \multirow[b]{3}{*}{ EST } & \multicolumn{3}{|l|}{ BLAST } & & & \\
\hline & \multirow[b]{2}{*}{ Best match ${ }^{\mathrm{a}}$} & \multirow[b]{2}{*}{ E-value } & \multirow{2}{*}{$\begin{array}{c}\text { Sequence } \\
\text { identity }(\%)\end{array}$} & \multicolumn{3}{|c|}{ Reverse northern ${ }^{\mathrm{b}}$} \\
\hline & & & & Mock & $\mathrm{R}$ & $\mathrm{S}$ \\
\hline \multicolumn{7}{|c|}{ Defense mechanisms } \\
\hline OSJNEd01P14 & $\beta-1,3-G l u c a n a s e(O r y z a$ sativa) (AAK16694) & e-169 & 90 & 3.9 & $6.2(+)^{\mathrm{c}}$ & 4.6 \\
\hline OSJNEd12G02 & Peroxidase (O. sativa) (P37834) & $2 \mathrm{e}-97$ & 59 & 1.4 & $2.5(+)$ & 2.0 \\
\hline \multicolumn{7}{|l|}{$\begin{array}{l}\text { Signal transduction } \\
\text { mechanisms }\end{array}$} \\
\hline OSJNEd02L21 & Protein phosphatase 2C (Arabidopsis thaliana) (NP_180133) & $4 e-64$ & 67 & 0.1 & $2.0(+)$ & $1.7(+)$ \\
\hline OSJNEd09I03 & $\begin{array}{l}\text { Benzothiadiazole (BTH)-induced protein phosphatase } 2 \mathrm{C} \text { (O. sativa) } \\
\text { (AAW29521) }\end{array}$ & $5 e-28$ & 82 & 3.9 & 3.2 & 3.0 \\
\hline OSJNEd09M06 & Phosphoesterase family protein $($ A. thaliana $)\left(\mathrm{NP}_{2}\right.$ 180255) & e-179 & 64 & 1.1 & 1.0 & 1.0 \\
\hline OSJNEd $15 N 10$ & Copine-related protein (A. thaliana) (NP_196946) & $3 e-22$ & 48 & 0.5 & $1.1(+)$ & $1.1(+)$ \\
\hline OSJNEd $16 \mathrm{H} 06$ & Serine/threonine protein kinase $\left(O\right.$. sativa) $\left(\mathrm{XP} \_550376\right)$ & 0 & 87 & 0.1 & $1.2(+)$ & $0.6(+)$ \\
\hline \multicolumn{7}{|c|}{$\begin{array}{l}\text { Posttranslational modi- } \\
\text { fication, protein turn- } \\
\text { over, and chaperones }\end{array}$} \\
\hline OSJNEd01N22 & $\begin{array}{l}\text { DnaJ heat shock N-terminal domain-containing protein (O. sativa) } \\
\text { (XP_464453) }\end{array}$ & 0 & 85 & 0.2 & $5.3(+)$ & $4.1(+)$ \\
\hline OSJNEd02O23 & Phosphatidylinositol glycan-related protein (A. thaliana) (NP_195278) & $\mathrm{e}-24$ & 51 & 4.0 & 4.5 & 3.0 \\
\hline OSJNEd04C23 & $\begin{array}{l}\text { Ribulose bisphosphate carboxylase/oxgenase activase (O. sativa) } \\
\text { (BAA97583) }\end{array}$ & 0 & 86 & 2.3 & $5.5(+)$ & 3.0 \\
\hline \multicolumn{7}{|c|}{$\begin{array}{l}\text { Information storage } \\
\text { and processing }\end{array}$} \\
\hline OSJNEd03C11 & rRNA intron-encoded homing endonuclease (O. sativa) (AAK13589) & $9 e-5$ & 70 & 1.1 & $2.7(+)$ & $2.0(+)$ \\
\hline OSJNEd06A05 & Ribosomal protein S19 (O. sativa) (CAA33927) & e-30 & 77 & 3.5 & $1.5(-)$ & 2.1 \\
\hline OSJNEd13E08 & RNA recognition motif-containing protein $(O$. sativa) (XP_479898) & $9 \mathrm{e}-71$ & 89 & 1.4 & $2.6(+)$ & 1.6 \\
\hline OSJNEd17B 11 & $\begin{array}{l}\text { U2 small nuclear ribonucleoprotein particle auxiliary factor }(\text { O. sativa }) \\
\text { (CAA77132) }\end{array}$ & e-107 & 100 & 0.1 & $0.8(+)$ & $0.3(+)$ \\
\hline \multicolumn{7}{|l|}{ Metabolism } \\
\hline OSJNEd01I23 & $\begin{array}{l}\text { NADH-ubiquinone oxidoreductase 19-kDa subunit (A. thaliana) } \\
\text { (NP_566280) }\end{array}$ & $6 e-42$ & 70 & 0.5 & $3.1(+)$ & $4.0(+)$ \\
\hline OSJNEd03M23 & Magnesium-chelatase subunit (Hordeum vulgare) (AAK72401) & e-132 & 90 & 4.0 & 3.0 & 4.5 \\
\hline OSJNEd03K22 & Calcium-binding EF-hand family protein (A. thaliana) (NP_194934) & $4 \mathrm{e}-18$ & 66 & 1.8 & $6.2(+)$ & $4.9(+)$ \\
\hline OSJNEd04J14 & Isocitrate lyase (O. sativa) (XP_478504) & e-159 & 94 & 3.0 & $5.4(+)$ & $4.6(+)$ \\
\hline OSJNEd05F08 & Auxin-induced protein (A. thaliana) (AAF17106) & e-94 & 80 & 3.9 & $6.1(+)$ & 4.5 \\
\hline OSJNEd05M22 & Monosaccharide transporter 6 (O. sativa) (AAQ24872) & $6 e-90$ & 91 & 4.2 & 4.0 & 3.0 \\
\hline OSJNEd12K13 & Cinnamyl alcohol dehydrogenase (O. sativa) (BAD28601) & e-93 & 78 & 1.6 & $4.4(+)$ & $3.0(+)$ \\
\hline \multicolumn{7}{|l|}{ Unclear function } \\
\hline OSJNEd02H15 & Proline rich protein (Lycopersicon esculentum) (Q00451) & $4 \mathrm{e}-25$ & 55 & 5.0 & $2.2(-)$ & $2.0(-)$ \\
\hline OSJNEd05C17 & Expressed protein $(A$. thaliana $)\left(\mathrm{NP}_{1} 172743\right)$ & $2 \mathrm{e}-4$ & 74 & 1.6 & $3.7(+)$ & 2.2 \\
\hline OSJNEd05D07 & Unknown protein (A. thaliana) (AAM61006) & $4 \mathrm{e}-48$ & 56 & 1.7 & $4.8(+)$ & $3.3(+)$ \\
\hline OSJNEd08A15 & Hypothetical protein (O. sativa) (BAD46202) & $7 e-18$ & 80 & 2.5 & $1.0(-)$ & 2.0 \\
\hline OSJNEd08P24 & Proline-rich family protein (A. thaliana) (NP_180843) & $8 \mathrm{e}-21$ & 40 & 2.7 & 2.1 & 1.5 \\
\hline OSJNEd10A03 & Unknown protein (A. thaliana) (NP_180587) & $8 \mathrm{e}-37$ & 36 & 7.5 & 5.6 & $2.2(-)$ \\
\hline OSJNEd12M07 & Putative stress inducible protein (O. sativa) (NP_921847) & e-112 & 85 & 1.9 & 2.3 & 1.8 \\
\hline OSJNEd16B11 & F-box-like protein (O. sativa) (XP_464891) & $3 e-81$ & 100 & 4.0 & 4.8 & 3.0 \\
\hline OSJNEd17A08 & Unknown protein (O. sativa) (AVV̄44205) & $8 \mathrm{e}-31$ & 98 & 0.4 & 0.3 & $0.6(+)$ \\
\hline
\end{tabular}

${ }^{a}$ ESTs were classified into putative functional groups using the NCBI database of Clusters of Orthologous Groups (COGs; provided online by the National Center for Biotechnology Information [NCBI]).

${ }^{\mathrm{b}}$ Mean signal intensity of hybridizations that were independently conducted twice. EST clones of OSJNEd cDNA rice library were spotted on nylon membranes and hybridized with radioactive-labeled cDNA probes made from St. Augustinegrass under the following three different conditions: FX-10 at $24 \mathrm{~h}$ after spraying with $0.02 \%$ Tween 20 solution (Mock); the incompatible reaction of FX-10 at $24 \mathrm{~h}$ after inoculation with Magnaporthe grisea isolate Che86061 (R); and the compatible reaction of Floratam at $24 \mathrm{~h}$ after inoculation with Che86061 (S). The hybridization intensity was quantified using digital image analysis software, Image $\mathbf{J}$ (provided online by the National Institutes of Health $[\mathrm{NIH}]$ ), corrected to the negative control hybridization and normalized as (intensity of the cDNA clone)/(intensity of the ubiquitin cDNA clone).

${ }^{c}$ Expression levels were increased (+) or decreased (-) more than 50\% after $M$. grisea inoculation compared with the mock inoculation. 
FX-10
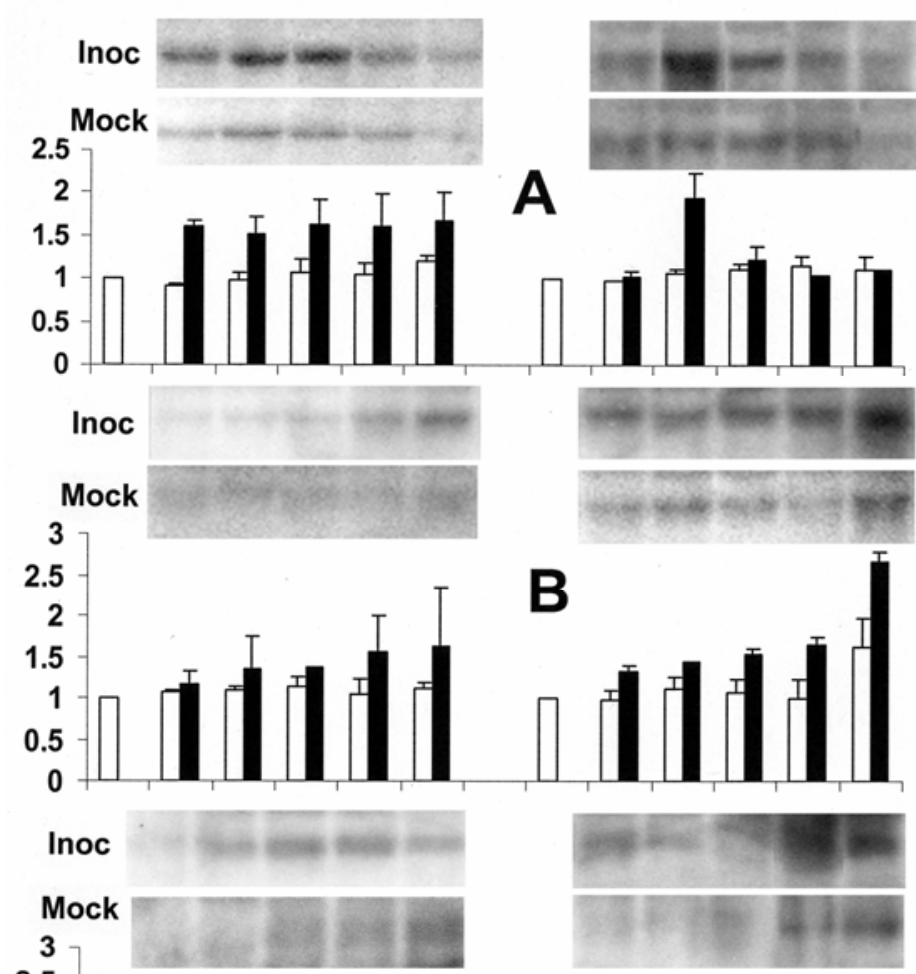

2.5

2
1.5

1.5

0.5

0
A
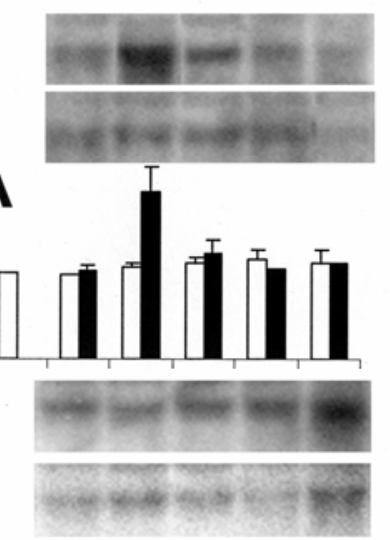

0.5

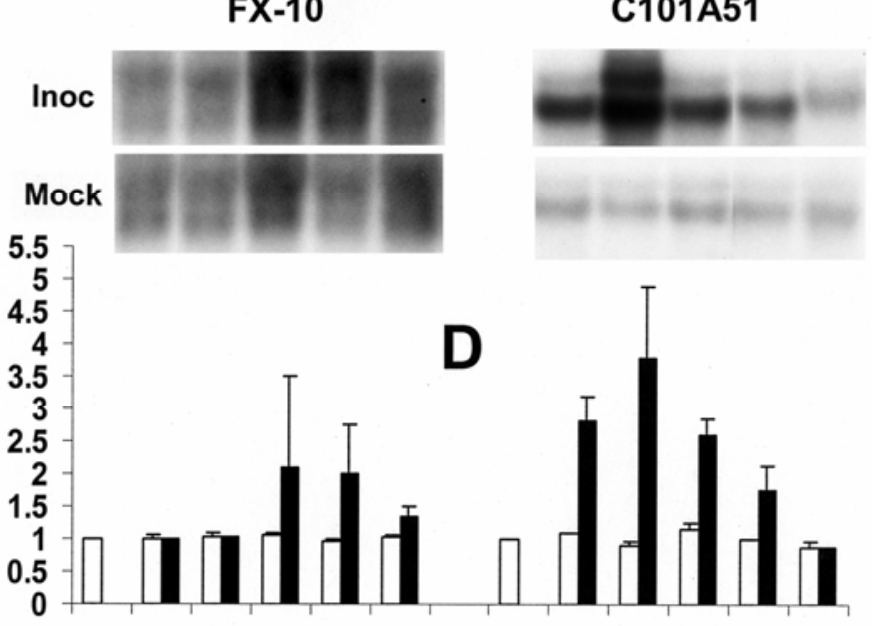

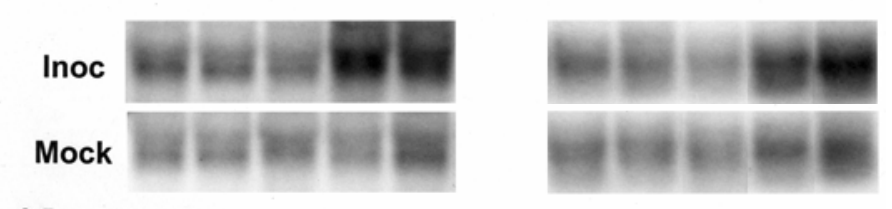

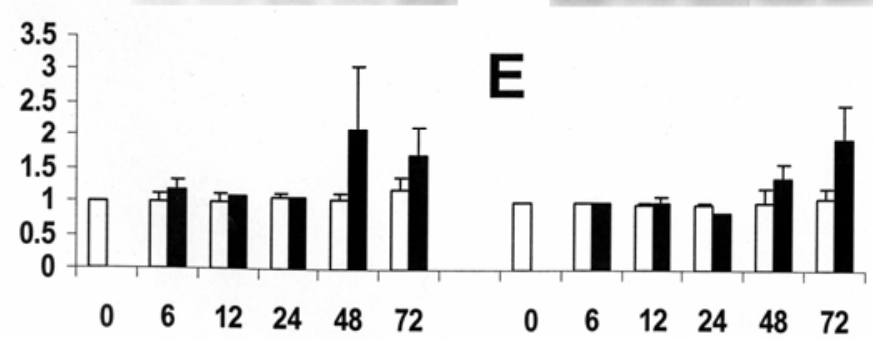

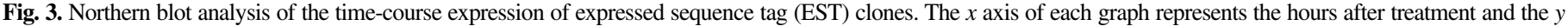

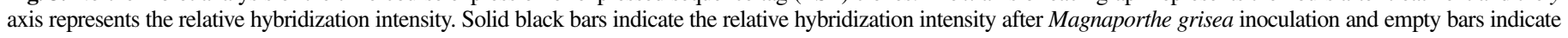

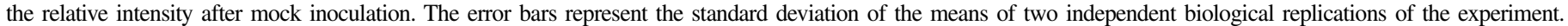

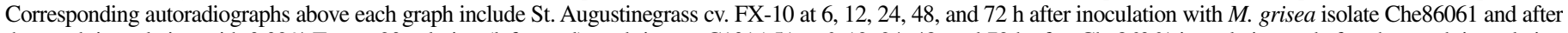

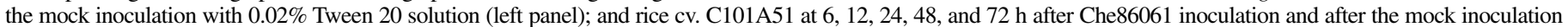

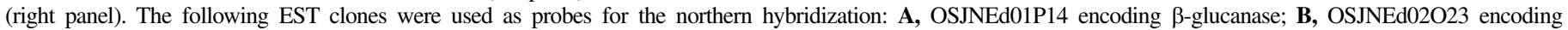

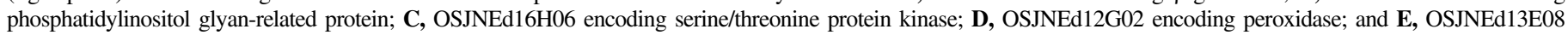
encoding RNA recognition motif-containing protein.

(OSJNEd01P14) and a peroxidase (OSJNEd12G02) increased in the virtual northern analysis. Both of these ESTs strongly hybridized with the cDNA probe generated from the incompatible reaction of St. Augustinegrass cv. FX-10 in the reverse northern analysis (Table 2). The increased expression of these ESTs in cv. FX-10 and rice cv. C101A51 following $M$. grisea infection was confirmed by northern blot analysis (Fig. 3A and D).

The inconsistency in the expression levels of the same EST clone between turfgrass and rice was also found in the comparison of EST expression levels between the virtual northern and experimental northern analyses. Nevertheless, around $50 \%$ of the ESTs analyzed in the reverse northern using St. Augustinegrass cDNA probes showed similar expression patterns in rice cv. Nipponbare (Table 3). Given the different inoculation conditions for reverse northern and virtual northern analyses, the observation that half of the selected ESTs showed a similar tendency of expression in both St. Augustinegrass and rice responding to M. grisea, supports the presence of homologous genes playing conserved functions associated with compatible and incompatible reactions in both host plants. Isolation and sequence analysis of the rice orthologous genes from turfgrass plants in the future will determine the sequence conservation of these genes in both species.

Genes corresponding to the EST clones selected in this study appear to be expressed in both resistant and susceptible plants.
However, this is not unexpected since expression level and timing of expression of genes may differ depending on the compatible or incompatible response in host plants (11). As shown in the M. griseainoculated rice EST analysis by Jantasuriyarat et al. (15), EST clones highly abundant in one library were shown by northern blot analysis to be induced in compatible and incompatible responses and to have different patterns of expression. In another study, some cDNA clones isolated by subtraction hybridizations had a similar hybridization intensity in both resistant and susceptible reactions (27). Timing of gene expression after $M$. grisea infection will need to be confirmed using northern blot or real-time PCR analysis for the additional EST clones identified in this study as being differentially expressed.

To our knowledge, this research represents the first attempt to describe the broad spectrum response of genes in St. Augustinegrass to GLS at the gene expression level using tools and genetic resources from rice, the model plant for monocot species. Recently developed rice EST libraries and their sequence database (MGOS) were utilized to conduct reverse northern, northern blot, and virtual northern analyses. Even with the limitations of using heterologous hybridization approaches across species, results from three different approaches revealed similar gene expression patterns in both rice and St. Augustinegrass responding to $M$. grisea. Many of the genes 
TABLE 3. Comparison of the expression levels of expressed sequence tags (ESTs) clones between reverse northern, northern, and virtual northern analyses

\begin{tabular}{|c|c|c|c|c|c|c|}
\hline \multirow[b]{2}{*}{ EST } & \multirow[b]{2}{*}{ Putative function } & \multicolumn{2}{|c|}{$\begin{array}{l}\text { Reverse northern } \\
\quad \text { (turfgrass) }\end{array}$} & \multirow{2}{*}{$\begin{array}{c}\text { Northern }^{\mathrm{b}} \\
\text { (turfgrass and rice) }\end{array}$} & \multicolumn{2}{|c|}{$\begin{array}{l}\text { Virtual northern } \\
\text { (rice) }\end{array}$} \\
\hline & & $\mathrm{R}$ & $\mathrm{S}$ & & $\mathrm{R}$ & $\mathrm{S}$ \\
\hline OSJNEd01P14 & $\beta$-Glucanase & + & 0 & + & + & + \\
\hline OSJNEd12G02 & Peroxidase & + & 0 & + & + & + \\
\hline OSJNEd $15 \mathrm{~N} 10$ & Copine-related & + & + & 0 & & \\
\hline OSJNEd16H06 & Serine/threonine protein kinase & + & + & + & & \\
\hline OSJNEd02O23 & Phosphatidylinositol glycan-related & 0 & 0 & + & & \\
\hline OSJNEd04C23 & Rubisco & + & 0 & & 0 & - \\
\hline OSJNEd03C11 & rRNA intron-encoded homing endonuclease & + & + & & 0 & 0 \\
\hline OSJNEd13E08 & RNA recognition motif-contained protein & + & 0 & + & & \\
\hline OSJNEd17B11 & U2 small nuclear ribonucleoprotein particle auxiliary factor & + & + & 0 & & \\
\hline OSJNEd04J14 & Isocitrate lyase & + & + & & + & + \\
\hline OSJNEd02H15 & Proline-rich protein & - & - & & - & - \\
\hline OSJNEd08A15 & Hypothetical protein & - & 0 & & 0 & 0 \\
\hline OSJNEd08P24 & Proline-rich protein & 0 & 0 & & + & + \\
\hline OSJNEd17A08 & Unknown protein & 0 & + & & 0 & 0 \\
\hline
\end{tabular}

${ }^{a}$ Hybridization intensity of ESTs with cDNA probes generated from St. Augustinegrass cvs. FX-10 (R) and Floratam (S) at $24 \mathrm{~h}$ after inoculation with Magnaporthe grisea isolate Che86061. The changes of hybridization intensities are expressed as increased $\geq 50 \%(+)$, decreased $\geq 50 \%(-)$, or not significant $(0)$ after $M$. grisea inoculation compared with the mock inoculation.

${ }^{\mathrm{b}}$ Expression of ESTs is increased (+) more than approximately twofold or not significant (0) in both St. Augustinegrass cv. FX-10 and rice cv. C101A51 after inoculation with $M$. grisea isolate Che86061 compared with the mock inoculation condition.

${ }^{c}$ Frequency of contigs corresponding to each EST in the incompatible library (R; OSJNEd) and compatible library (S; OSJNEb) compared with the control library (OSJNEf) of rice cv. Nipponbare (Magnaporthe grisea Oryza sativa [MGOS] interactive database provided online by the National Science Foundation). The incompatible library contains cDNA from Nipponbare at $24 \mathrm{~h}$ after inoculation with $M$. grisea isolate C9240-1; the compatible library contains cDNA from Nipponbare at $24 \mathrm{~h}$ after inoculation with $M$. grisea isolate Che86061; and the control library contains cDNA from water-treated Nipponbare. The virtual northern analysis is conducted for ESTs only if more than 30 contigs corresponding to the ESTs are found from these cDNA libraries. More than five times more $(+)$ or less (-) contigs are found in the incompatible or compatible library compared with the control library.

screened in this study are homologous to previously known genes that are associated with plant defense and stress responses. The change of expression of selected ESTs was correlated with resistance phenotypes. This suggests that similar genes are involved in mediating plant defense responses in both St. Augustinegrass and rice, and agrees with recent findings of a high level of synteny between genomes of ryegrass and cereal crops $(16,27)$. Further large-scale sequencing of ESTs or construction of suppression subtractive hybridization cDNA libraries using $M$. griseainoculated turfgrass will facilitate the identification and characterization of defense-related genes in turfgrass, and enable the comparative study of defense-related genes responding to $M$. grisea infection in these graminaceous plants.

\section{ACKNOWLEDGMENTS}

We thank R. Nagata and L. Datnoff at University of Florida, Belle Glade, for providing St. Augustinegrass and M. grisea-infected plant materials, and P. Redinbaugh and S. Kamoun for critical review of this manuscript. Support for this project was provided by the Ohio Turfgrass Foundation, and state and federal funds appropriated to the Ohio Agricultural Research and Development Center.

\section{LITERATURE CITED}

1. Atilano, R. A., and Busey, P. 1983. Susceptibility of St. Augustinegrass germ plasm to Pyricularia grisea. Plant Dis. 67:782-783.

2. Benkirane, R., Douira, A., Selmaoui, K., and Lebbar, S. 2000. Comparative pathogenesis and mating type of Moroccan isolates of Pyricularia grisea (Magnaporthe grisea) from rice and Stenotaphrum secundatum. J. Phytopathol. 148:95-99.

3. Bonos, S. A., Kubik, C., Clarke, B. B., and Meyer, W. A. 2004. Breeding perennial ryegrass for resistance to gray leaf spot. Crop Sci. 44:575-580.

4. Busey, P. 1986. Morphological identification of St. Augustinegrass cultivars. Crop Sci. 26:28-32.

5. Busey, P. 1990. Polyploid stenotaphrum germplasm: Resistance to the polyploid damaging population southern chinch bug. Crop Sci. 30:588593.

6. Chen, H., Wang, S., Xing, Y., Xu, C., Hayes, P. M., and Zhang, Q. 2003. Comparative analyses of genomic locations and race specificities of loci for quantitative resistance to Pyricularia grisea in rice and barley. Proc. Natl. Acad. Sci. USA 100:2544-2549.
7. Farman, M. L. 2002. Pyricularia grisea isolates causing gray leaf spot on perennial ryegrass (Lolium perenne) in the United States: Relationship to. P. grisea isolates from other host plants. Phytopathology 92:245-254.

8. Fraser, M. L. 1997. Susceptibility of tall fescues to gray leaf spot. Biol. Cult. Tests 12:130.

9. Gibbons, J. D. 1976. Nonparametric Methods for Quantitative Analysis. Holt, Rinehart and Winston, New York.

10. Goff, S. A., Ricke, D., Lan, T. H., Presting, G., Wang, R., Dunn, M., Glazebrook, J., Sessions, A., Oeller, P., Varma, H., Hadley, D., Hutchison, D., Martin, C., Katagiri, F., Lange, B. M., Moughamer, T., Xia, Y., Budworth, P., Zhong, J., Miguel, T., Paszkowski, U., Zhang, S., Colbert, M., Sun, W. L., Chen, L., Cooper, B., Park, S., Wood, T. C., Mao, L., Quail, P., Wing, R., Dean, R., Yu, Y., Zharkikh, A., Shen, R., Sahasrabudhe, S., Thomas, A., Cannings, R., Gutin, A., Pruss, D., Reid, J., Tavtigian, S., Mitchell, J., Eldredge, G., Scholl, T., Miller, R. M., Bhatnagar, S., Adey, N., Rubano, T., Tusneem, N., Robinson, R., Feldhaus, J., Macalma, T., Oliphant, A., and Briggs, S. 2002. A draft sequence of the rice genome (Oryza sativa L. sp. japonica). Science 296:92-100.

11. Graham, T. L., and Graham, M. Y. 1991. Cellular coordination of molecular responses in plant defense. Mol. Plant-Microbe Interact. 4:415422.

12. Grunstein, M., and Hogness, D. S. 1975. Colony hybridization: A method for the isolation of cloned DNAs that contain a specific gene. Proc. Natl. Acad. Sci. USA 72:3961-3965.

13. Harmon, P., Rane, K., Ruhl, G., and Latin, R. 2000. First report of gray leaf spot on perennial ryegrass in Indiana. Plant Dis. 84:492.

14. Horn, G. C., Dudeck, A. E., and Toler, R. W. 1973. 'Floratam' St. Augustinegrass: A fast growing new variety for ornamental turf resistant to St. Augustine decline and chich bugs. Florida Agric. Exp. Stn. Circ. S224.

15. Jantasuriyarat, C., Gowda, M., Haller, K., Hatfield, J., Lu, G., Stahlberg, S., Zhou, B., Li, H., Kim, H., Yu, Y., Dean, R. A., Wing, R. A., Soderlund, C., and Wang, G. 2005. Large-scale identification of expressed sequence tags involved in rice and rice blast fungus interaction. Plant Physiol. 138:105-115.

16. Jones, E. S., Mahoney, N. L., Hayward, M. D., Armstead, H., Jones, J. G., Humphreys, M. O., King, I. P., Kishida, T., Yamada, T., Balfourier, F., Charmet, G., and Forster, J. W. 2002. An enhanced molecular marker based genetic map of perennial ryegrass (Lolium perenne) reveals comparative relationships with other Poaceae genomes. Genome 45:282-295

17. Kato, H., Yamamoto, M., Yamaguchi-Ozaki, T., Kadouchi, H., Iwamoto, Y., Nakayashiki, H., Tosa, Y., Mayama, S., and Mori, N. 2000. Pathogenicity, mating ability and DNA restriction fragment length polymorphisms of Pyricularia populations isolated from Gramineae, Bambusideae and Zingiberaceae plants. J. Gen. Plant Pathol. 66:30-47. 
18. Liu, G., Lu, G., Zeng, L., and Wang, G. L. 2002. Two broad-spectrum blast resistance genes, $P i 9(t)$ and $P i 2(t)$, are physically linked on rice chromosome 6. Mol. Genet. Genomics 267:472-480.

19. Lu, G., Jantasuriyarat, C., Zhou, B., and Wang, G. L. 2004. Isolation and characterization of novel defense response genes involved in compatible and incompatible interactions between rice and Magnaporthe grisea. Theor. Appl. Genet. 108:525-534.

20. Mackill, A. O., and Bonman, J. M. 1986. New hosts of Pyricularia oryzae. Plant Dis. 70:125-127.

21. McCouch, S. R., Nelson, R. J., Tohme, J., and Zeigler, R. S. 1994. Mapping of blast resistance genes in rice. Pages 167-186 in: Rice Blast Disease. R. S. Zeigler, S. A. Leong, and P. S. Teng, eds. CAB International (Commonw. Agric. Bureaux), London.

22. Pedersen, D. K., Kane, R. T., and Wilkinson, H. T. 2000. First report of gray leaf spot caused by Pyricularia grisea on Lolium perenne in Illinois. Plant Dis. 84:1151.

23. Peyyala, R., and Farman, M. L. 2006. Magnaporthe oryzae isolates causing gray leaf spot of perennial ryegrass possess a functional copy of the AVR1-CO39 avirulence gene. Mol. Plant Pathol. 7:157-165.

24. Rossman, A. Y., Howard, R. J., and Valent, B. 1990. Pyricularia grisea, the correct name for the rice blast disease fungus. Mycologia 82:509-512.

25. Sambrook, J., and Russell, D. W. 2000. Molecular Cloning: A Laboratory Manual. 3rd ed. Cold Spring Harbor Laboratory, Cold Spring Harbor, NY.

26. Schumann, G. L., and Jackson, N. 1999. First report of gray leaf spot (Pyricularia grisea) on perennial ryegrass (Lolium perenne) in New England. Plant Dis. 83:1073.

27. Sim, S., Chang, T., Curley, J., Warnke, S. E., Barker, R. E., and Jung, G. 2005. Chromosomal rearrangements differentiating the ryegrass genome from the Triticeae, oat, and rice genomes using common heterologous RFLP probes. Theor. Appl. Genet. 110:1011-1019.

28. Tosa, Y., Hirata, K., Tamba, H., Nakagawa, S., Chuma, I., Isobe, C., Osue, J., Urashima, A. S., Don, L. D., Kusaba, M., Nakayashiki, H., Tanaka, A., Tani, T., Mori, N., and Mayama, S. 2004. Genet-ic constitution and pathogenicity of Lolium isolates of Magnaporthe oryzae in comparison with host species-specific pathotypes of the blast fungus. Phytopathology 94:454-462.

29. Uddin, W., Viji, G., and Stowell, L. 2002. First report of gray leaf spot on perennial ryegrass turf in California. Plant Dis. 86:75.

30. Uddin, W., Viji, G., and Vincelli, P. 2003. Gray leaf spot (blast) of perennial ryegrass turf: An emerging problem for the turfgrass industry. Plant Dis. 87:880-889.

31. Urashima, A. S., Igarashi, S., and Kato, H. 1993. Host range, mating type, and fertility of Pyricularia grisea from wheat in Brazil. Plant Dis. 77:1211-1216

32. Valent, B., Farrall, L., and Chumley, F. G. 1986. Genetic studies of fertility and pathogenicity in Magnaporthe grisea (Pyricularia oryzae). Iowa State J. Res. 60:569-594.

33. Vargas, J. M., Jr. 1994. Management of Turfgrass Diseases. Lewis Publishers, Boca Raton, FL.

34. Viji, G., Wu, B., Kang, S., Uddin, W., and Huff, D. R. 2001. Pyricularia grisea causing gray leaf spot of perennial ryegrass turf: Population structure and host specificity. Plant Dis. 85:817-826.

35. Vincelli, P., and Dixon, E. 2002. Resistance to QoI (strobilurin-like) fungicides in isolates of Pyricularia grisea from perennial ryegrass. Plant Dis. 86:235-240.

36. Wang, G. L., Mackill, D. J., Bonman, J. M., McCouch, S. R., Champoux, M. C., and Nelson, R. J. 1994. RFLP mapping of genes conferring complete and partial resistance to blast in a durably resistant rice cultivar. Genetics 136:1421-1434.

37. Wang, Z. X., Yano, M., Yamanouchi, U., Iwamoto, M., Monna, L., Hayasaka, H., Katayose, Y., and Sasaki, T. 1999. The Pib gene for rice blast resistance belongs to the nucleotide binding and leucine-rich repeat class of plant disease resistance genes. Plant J. 19:55-64.

38. Xiao, F., Tang, X., and Zhou, J. M. 2001. Expression of 35S:Pto globally activates defense-related genes in tomato plants. Plant Physiol. 126:16371645. 